\title{
COMPARISON OF SHEAR BOND STRENGTH OF METAL AND CERAMIC ORTHODONTIC BRACKETS AFTER ADDING NANOPARTICLES OF SILVER
}

\author{
Yousef M. Althomali*
}

\begin{abstract}
Objective: To evaluate effect of nanoparticles of silver (NAg) added on Nano-Bond adhesive system and its effect on shear bond strength of brackets attached to enamel.

Materials and methods: Thirty extracted premolar teeth for orthodontic reasons were divided into two groups; First group metal brackets and second group the ceramic brackets were bonded by Nano-Bond adhesive system containing (NAg) with concentration $0.05 \%$. Every group was further subdivided into 2subgroups with 5 teeth each; Groups A1, B1 (Teeth not subjected to thermocycling and cyclic loading), Groups A2, B2 [(Teeth subjected to thermocycling (500cycles) and cyclic loading (90N, 0.8-1 cycles/sec. 100,000 cycles)]

Enamel etched then the adhesives were applied to the entire enamel surface according to bonding agent containing (NAg) or not, then light cured for 10 seconds with LED. The base of brackets were filled by nano-filled composite resin and placed on the tooth and cured by LED for 40 seconds. The recorded values of bond strengths in (MPa) were collected, tabulated and statistically analyzed. One way analysis of variance (ANOVA) and Tukey's tests were used for testing the significance between the means of tested groups which are statistically significant when the $P$ value $\leq 0.05$.
\end{abstract}

Results: shear bond strength of metal brackets bonded by Nano-Bond adhesive containing nanoparticles of silver (NAg) (Group A) was significantly higher than shear bond strength of ceramic brackets (group B).

Conclusions: The adhesive shear strengths are high for metal bracket bonded by Nano-Bond adhesive system containing nanoparticles of silver (NAg) with concentration $0.05 \%$ than ceramic bracket.

\section{INTRODUCTION}

More adults are seeking orthodontic treatment and demanding esthetic or invisible appliances ${ }^{1}$. Ceramic brackets were introduced to meet this need, and their popularity is increasing ${ }^{2,3}$. The ceramic brackets currently on the market are made of aluminum oxide and are chemically inert to oral fluids ${ }^{4,5}$.

* Assistant Professor Department of Orthodontic, Faculty of Dental Medicine, Taif University, Taif, Saudi Arabia. 
Although these brackets offer better esthetics, enamel fractures and cracks have been reported during debonding procedures. Increased bond strength usually results in bond failure at the enamel surface, rather than at the bracket-adhesive interface. Consequently, the continuing challenge is to develop a bond between orthodontic attachments and the enamel that is strong enough to accomplish treatment but can be broken for debonding without damage to the enamel surface ${ }^{6}$.

The majority of complaints are regarding the discomfort encountered during the debonding phase of treatment. One of the crises the clinicians may face during treatment is bracket failure. This usually the outcome of either applying improper force to the bracket or due to deprived bonding techniquestudies have shown that clinical bond failure occurs with $5 \%$ to $7 \%$ of brackets bonded with light cure or chemical cure composite resins for different reasons ${ }^{7}$.

Measurement of shear bond strength is the most commonly used laboratory method to evaluate the performance of orthodontic bonding systems and a variety of techniques have been applied for shear bond strength measurements ${ }^{2}$. However, the lack of standardization of bond strength testing and the large distribution of results often prevent confident conclusions from being drawn ${ }^{8-10}$. Shear tests typically involve a combination of shear and peel forces because force is applied at a distance from the bonding interface ${ }^{11,12}$.

The bonding procedure is based on enamel alteration created by acid etching of the enamel as developed by Buounocore (1955) ${ }^{13}$.

Phosphoric acid is used in the form of a solution or gel etches at a concentration of $37 \%$. The acid is applied on enamel surface thus cleanses the surface and improves the wettability of enamel by the resin. It also causes selective dissolution of enamel rods. The acid removes calcium salts from enamel, thus increases the size and number of micro spaces present in the enamel surface which is normally porous. When the resin is applied on such etched enamel surface, it can penetrate into micro spaces or irregularities, thus producing "resin tag" (finger like projections) with subsequent increase in bond strength and reduction of marginal staining and discoloration ${ }^{14}$.

The use of bonding agents is known from restorative dentistry that it improves the adhesion of composite resins. The bonding agents create a micro-mechanical interlock between the dentin collagen and resin by forming the hybrid layers ${ }^{15}$.

Bonding agents were adhere composite restoration to tooth structure to form a functional and durable interface ${ }^{16-18}$. Bonding agent compositions and bond strengths have been improved in previous studies ${ }^{19,20}$. Antibacterial adhesives are promising to combat bacteria and reduce recurrent caries at the tooth-restoration margins ${ }^{21,22}$.

Nano-sized filler such as nano-sized aerosol silica filler were introduced to bonding agents by mean of nano technology. The nanofillers technology is claimed to increase adhesion to both enamel and dentin and improves marginal integrity ${ }^{23}$.

Recently, a quaternary ammonium dimethacrylate (QADM) was synthesized and incorporated into resins to inhibit biofilm growth ${ }^{24,25}$. In addition, recent studies developed antibacterial nanocomposites containing nanoparticles of silver (NAg) with a potent antibacterial activity ${ }^{26}$. Hence, the cured QADM-containing adhesive could inhibit bacteria adherent on its surface, but would have no effect on bacteria in the culture medium away from its surface $^{27}$.

The resin containing NAg inhibit not only bacteria on its surface, but also bacteria in the culture medium away from its surface due to $\mathrm{Ag}$ ion ${ }^{28}$. For dental composites, it is desirable to incorporate silver nanoparticles with a high surface area into the resin to reduce the $\mathrm{Ag}$ particle concentration 
necessary for efficacy ${ }^{29}$. Low Ag filler levels in the resin would not affect the resin color ${ }^{25}$.

Thermocycling is defined as the in vitro process of subjecting a restoration and tooth to temperature extremes that conform to those found in the oral cavity $^{29}$. Thermocycling considered cycling regimes employing short dwell time to be more realistic clinically ${ }^{31}$. Cyclic loading application was made to simulate clinical occlusal stress condition in oral cavity $^{32}$.

The purpose of this study was to evaluate the effect of adding nanoparticles of silver (NAg) with concentration $0.05 \%$ into Nano-Bond adhesives on shear bond strength of brackets attached to enamel.

\section{MATERIALS AND METHODS}

An in vitro study was conducted to test the shear bond strength of orthodontic brackets after adding nanoparticles of silver (NAg) with concentration $0.05 \%$ on nano-bond adhesive.

One type of adhesive available system was used as the control [Nano-Bond adhesive (Pentron Clinical technologies, USA, lot \# 183421)], nanoparticles of silver (NAg) with concentration $0.05 \%$ was added into Nano-Bond adhesives, one type of nano-filled composite resin (Artiste Nanocomposite, Pentron Clinical technologies LLc, USA, lot \# 182066-185215) and two type of orthodontics brackets: metal bracket $(0.022 \times 0.028)$ (Global orthodontics, LLc, Chanlitity USA) and ceramic bracket (Crystaline;Tomy, Tokyo, Japan) were used in this study.

Twenty caries- free freshly extracted human maxillary premolar teeth were collected to be used in this study. The teeth were cleaned by ultrasonic scaler and stored in distilled water at $37^{\circ} \mathrm{C}$ before testing.
Teeth were embedded in chemically cured dental acrylic (Palavit G, Heraeus Kulzer, Wehrheim,Germany) in plastic cylinders to allow for standardized and secure placement during testing.

Teeth were randomly divided into two main groups (10 each) according to the bonding agent containing nanoparticles of silver (NAg). Group A: The metal brackets were bonded by Nano-Bond adhesive system containing nanoparticles of silver (NAg) with concentration $0.05 \%$ and Group B: The ceramic brackets were bonded by Nano-Bond adhesive system containing nanoparticles of silver (NAg) with concentration $0.05 \%$

\section{Grouping of the teeth}

TABLE (1) Every group was further subdivided into 2 subgroups with 5 teeth

\begin{tabular}{|c|c|c|c|}
\hline Groups & Subgroups & Description & $\begin{array}{c}\text { No. of } \\
\text { Specimens }\end{array}$ \\
\hline \multirow[b]{2}{*}{ 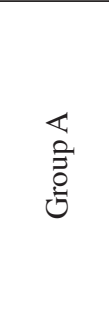 } & Group A1 & $\begin{array}{l}\text { Teeth not subjected to } \\
\text { cyclic loading. }\end{array}$ & 5 specimens \\
\hline & Group A2 & $\begin{array}{l}\text { Teeth subjected to ther- } \\
\text { mocycling (500cycles) } \\
\text { and cyclic loading } \\
(90 \mathrm{~N}, 0.8-1 \text { cycles } / \mathrm{sec} \text {. } \\
100,000 \text { cycles). }\end{array}$ & 5 specimens \\
\hline \multirow[b]{2}{*}{ 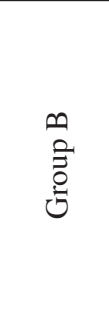 } & Group B1 & $\begin{array}{l}\text { Teeth not subjected to } \\
\text { cyclic loading. }\end{array}$ & 5 specimens \\
\hline & Group B2 & $\begin{array}{l}\text { Teeth subjected to ther- } \\
\text { mocycling ( } 500 \text { cycles) } \\
\text { and cyclic loading } \\
(90 \mathrm{~N}, 0.8-1 \text { cycles } / \mathrm{sec} \text {. } \\
100,000 \text { cycles). }\end{array}$ & 5 specimens \\
\hline & & Total & 20 specimens \\
\hline
\end{tabular}

Each enamel was acid etched using $37 \%$ phosphoric acid gel* for 15 seconds. Then the enamel was rinsed with water spray and dried with oil free stream for 5 seconds. Apply primer on etched enamel surface by using the applicator brush.

\footnotetext{
* Eco-Etch. Ivoclar vivadent.
} 
Remove the excess primer with a dry applicator brush, but leave the surface with a very wet appearance, Then light cured for 10 seconds with light emitting diodes* (LED).

The adhesives were applied to the entire enamel surface according to bonding agent containing nanoparticles of silver (NAg) or not, then air thinning for 15 seconds. A gentle stream of dry air was applied to disperse the material into a thin, uniform, shiny appearing surface. The adhesive was then light cured for 10 seconds with LED.

The base of brackets were filled by flowable composite resin and placed on the tooth and pressed firmly onto the surface. Any excess of the flowable composite resin was removed and the flowable composite resin was cured by LED for 40 seconds with the tip close to the surface as possible $(20 \mathrm{~s}$ from mesial and $20 \mathrm{~s}$ from distal).

Curing radiometer equipment** used to ensure steady light intensity throughout the polymerization of all specimens.

The specimens were stored in distilled water for 24 hours in $37^{\circ} \mathrm{C}$ before testing according to American dental association (ANSI/ADA) ${ }^{33}$ and International Organization for standardization $(\mathrm{ISO})^{34}$ for direct filling resins and dental adhesion.

\section{Thermocycling}

All teeth were stored in water at $37^{\circ} \mathrm{C}$ for 24 hours before being subjected to thermocycling, and then subjected to thermocycling to simulate clinical thermal stress condition. The teeth were stored alternatively in water reservoirs at $5^{\circ} \mathrm{C}$ and $55^{\circ} \mathrm{C}$ respectively, remaining in each reservoir for 30 seconds. This procedure was carried out (500 cycles) for group A2, B2 controlled by a computer.

\section{Cyclic loading}

A cyclic loading was applied to the tooth at a $45^{\circ}$ angle to the long axis of the tooth using Lloyd universal testing machine (model LRX plus II. Fareham, England) with a load cell of $5 \mathrm{kN}$ and data were recorded using computer software (NexygenMT 4.5.1; Lloyd Instruments).

A steel rod (0.8 $\mathrm{mm}$ diameter) attached to the upper movable compartment of the machine, applied to the middle part of tooth surface, load profile in the form of a sine wave at a rate of $1 \mathrm{~Hz}$. The rate was used as equivalent to the average masticatory cycle of $0.8-1.0 \mathrm{~s}^{35}$.

A force about $90 \mathrm{~N}$ was applied during fatigue test. This reflects normal chewing forces ${ }^{36}$.

Clinically, teeth are subjected to masticatory forces under dry and wet conditions ${ }^{37}$. In vitro studies should replicate the clinical conditions, and thus various methods have been developed to simulate oral environment such as cyclic loading fatigue ${ }^{38}$.

Groups A1, B1: Teeth not subjected to cyclic loading.

Groups A2, B2: Teeth subjected to cyclic loading (90N, 0.8-1 cycles/sec. 100,000 cycles) to simulate clinical occlusal stress condition after six months ${ }^{36}$.

\section{Shear bond Strength testing:}

Shear bond testing was done using Lloyd universal testing machine (model LRX plus II. Fareham, England). A specially designed upper attachment knife-edge was used.

The plastic cylinders with the embedded teeth and the brackets were mounted on a joint (lower attachment) and were aligned in the testing apparatus to ensure consistency for the point of force application and direction of the debonding force for 
all specimens. The direction of the debonding force was parallel to the enamel surface in an occlusogingival direction which shown in Fig 1. The load was applied perpendicularly to the interface of tooth and bracket at a cross head speed of $0.5 \mathrm{~mm} / \mathrm{min}$ until debonding occurred.

The shear bond strength in $\mathrm{Kg} / \mathrm{Cm}^{2}$ was calculated from the equation:

$$
\sigma s=\mathrm{P} / \pi \cdot r^{2}
$$

Where:

$$
\begin{aligned}
& \text { os: shear bond strength in } \mathrm{Kg} / \mathrm{Cm}^{2} \\
& \begin{aligned}
\mathrm{P} & \text { is the shear load in } \mathrm{Kg} \\
\pi & =3.14 \\
\mathrm{r} & \text { is the radius of the specimen in } \mathrm{Cm}
\end{aligned}
\end{aligned}
$$

The shear bond strength was converted to $\mathrm{MPa}$ by multiplying the results by 0.09807 .

The loads at failure were recorded and the data were analyzed by one way analysis of variance (ANOVA) and Tukey's tests were used for testing the significance between the means of tested materials which statistically significant when the $P$ value $\leq 0.05$.

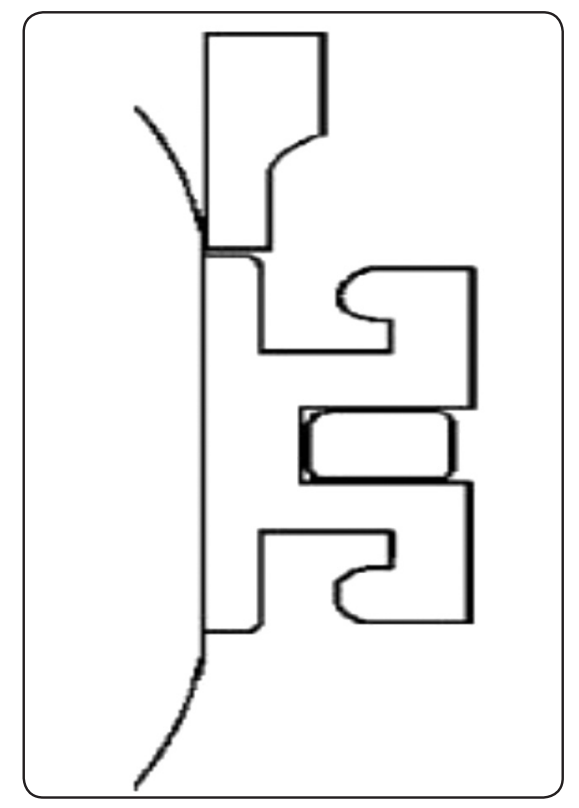

Fig. (1) Diagram of force application during debonding.

\section{RESULT}

The result of this study showed that the comparison between metal and ceramic brackets bonded by Nano-Bond adhesive system containing nanoparticles of silver (NAg) with concentration $0.05 \%$ [group A and Group B]

The mean percentage for the tested Nano-Bond adhesive system containing nanoparticles of silver (NAg) with concentration $0.05 \%$ which teeth not subjected to cyclic loading are presented in table 2 and figure 2 .

The metal brackets bonded by Nano-Bond adhesive system containing nanoparticles of silver (NAg) with concentration $0.05 \%$ (group A2) showed that the statistically significantly highest mean shear bond strength [20.25 MPa] than ceramic brackets bonded by Nano-Bond adhesive system containing nanoparticles of silver (NAg) with concentration $0.05 \%$ [14.86 MPa] (group B2).

The results of shear bond strength showed significant difference $(\mathrm{P}<0.05)$ between group $\mathrm{A} 2$ and group B2.

TABLE (2) Comparison between mean shear bond strength in (MPa) of the metal and ceramic brackets bonded by Nano-Bond adhesive system containing nanoparticles of silver (NAg) with concentration $0.05 \%$ which teeth not subjected to cyclic loading (group A1 and group B1):

\begin{tabular}{|c|c|c|c|c|}
\hline \multicolumn{2}{|c|}{ Group A1 } & \multicolumn{2}{c|}{ Group B1 } & \multirow{2}{*}{ P-value } \\
\cline { 1 - 3 } Mean & SD & Mean & SD & \multirow{2}{*}{$0.000^{*}$} \\
\hline $20.25^{\mathrm{a}}$ & 0.56 & $14.86^{\mathrm{b}}$ & 0.86 & \\
\hline
\end{tabular}

* Significant at $P \leq 0.05$, Means with different letters are significantly different according to Tukey's test. 


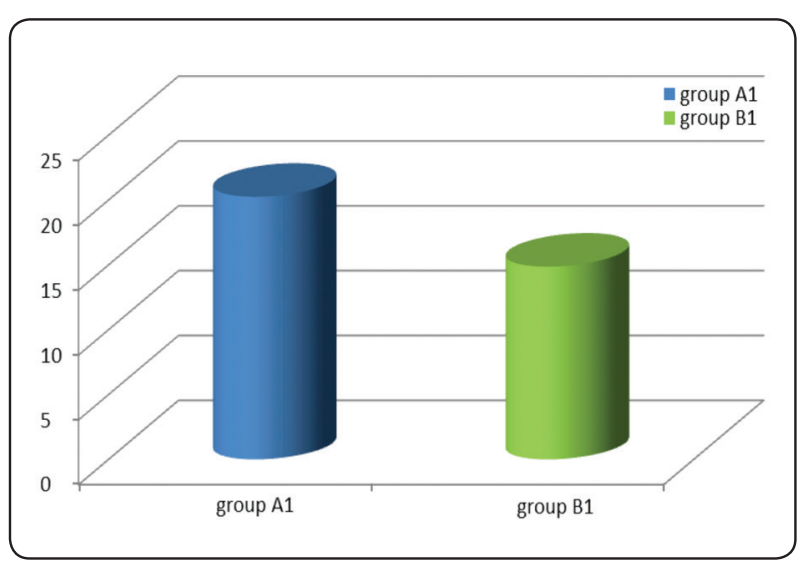

Fig. (2) Bar chart of mean shear bond strength in (MPa) of the tested Nano-Bond adhesive system groups (group A1 and group B1).

Both table 3 and figure 3 shows the comparison between mean shear bond strength in (MPa) of the teeth subjected to thermocycling (500cycles) and cyclic loading (100,000 cycles) (group A2 and group B2)

Group A2 showed that the statistically significantly highest mean shear bond strength (16.75 MPa) than group B2 (11.25 MPa).

The results of shear bond strength showed significant difference $(\mathrm{P}<0.05)$ between group B2 and group A2. Shear bond strength was increased for the specimens of the metal brackets than ceramic brackets (NAg).

TABLE (3) Comparison between mean shear bond strength in $(\mathrm{MPa})$ of the tested NanoBond adhesive system groups (group A2and group B2):

\begin{tabular}{|c|c|c|c|c|}
\hline \multicolumn{2}{|c|}{ Group A2 } & \multicolumn{2}{c|}{ Group B2 } & \multirow{2}{*}{ P-value } \\
\cline { 1 - 3 } Mean & SD & Mean & SD & \\
\hline $16.75^{\mathrm{a}}$ & 0.87 & $11.25^{\mathrm{b}}$ & 0.46 & $0.000^{*}$ \\
\hline
\end{tabular}

* Significant at $P \leq 0.05$, Means with different letters are significantly different according to Tukey's test.

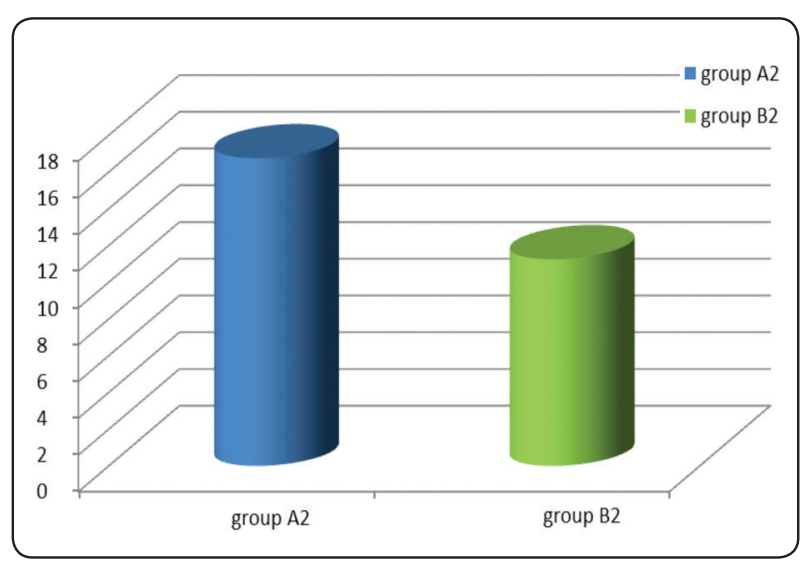

Fig. (3) Bar chart of mean shear bond strength in (MPa) of the tested Nano-Bond adhesive system groups (group A2 and group B2).

\section{DISCUSSION}

The use of ceramic brackets in orthodontics provides greatly improved esthetics, but results in problems during debonding. In clinical use, the bond between the ceramic bracket and the adhesive must be strong enough to withstand orthodontic and chewing forces while still allowing removal of the bracket without injury to the tooth.

The adhesive shear strengths recorded in this investigation are high for metal bracket bonded by Nano-Bond adhesive system containing nanoparticles of silver (NAg) with concentration $0.05 \%$ than ceramic bracket.

The data show that the metal brackets [groupA1, A2] had higher mean bond strength (20.25, $16.75 \mathrm{MPa}$ ) respectively than ceramic brackets [group B1, B2] $(14.86,11.25 \mathrm{MPa})$ respectively.

Bracket de-bonding resulting from factors, such as failure in the bonding technique, low retentiveness of certain bracket bases, masticatory forces $^{39-41}$ and reduced size of the bracket base for esthetic reasons, are common shortcomings in clinical orthodontics, and might delay treatment completion and increase the costs relative to the maintenance of fixed orthodontic appliances. With the objective of minimizing these problems, several 
solutions have been proposed such as aluminumoxide sandblasting and primer application ${ }^{42}$.

The bonding procedure is based on enamel alteration created by acid etching of the enamel as developed by Buounocore (1955) ${ }^{13}$.

Etching tooth enamel with phosphoric acid creates surface microporosities and irregularities into which low-viscosity resins can readily flow. This formation of mechanical retention by cured resin on phosphoric acid-etched enamel has been the major factor responsible for the enamel adhesion of resin-based composite ${ }^{43}$.

The acid removes calcium salts from enamel, thus increases the size and number of micro spaces present in the enamel surface which is normally porous. When the resin is applied on such etched enamel surface, it can penetrate into micro spaces or irregularities, thus producing "resin tag" (finger like projections) with subsequent increase in bond strength and reduction of marginal staining and discoloration ${ }^{14}$ and it is the major factor responsible for the adhesion of dental resins to enamel ${ }^{44}$.

According to many investigators ${ }^{34}$ the uses of filled adhesive resin increases the mechanical properties and improve marginal and internal seal of composite restoration. This was based on change in the stress dynamics at enamel/composite/adhesive resin interface. This creates an environment in which crack initiation and propagation would be less than non-filled adhesive ${ }^{45}$.

These adhesives may be categorized as mild or strong adhesives, depending on their $\mathrm{PH}$ and therefore their etching potential ${ }^{46}$.

The thermocycling procedure was performed on the samples to simulate the clinical conditions. This procedure simulates thermal conditions of oral environment. Intraoral temperature changes affect the mechanical properties of adhesive layer and generate thermal stresses in the adhesive layer, teeth surface and bracket ${ }^{47}$.
Shear bond strength test have been widely used, mainly because of their relative simplicity when compared to tensile bond strength test, in which it is difficult to align the specimen in the testing machine without creating deleterious stress distribution ${ }^{48,49}$. Advantages in shear tests include of specimen preparation and simple test protocol ${ }^{50}$.

The present study used nanoparticles of silver (NAg) with concentration $0.05 \%$ in adhesive because NAg was shown to possess potent antibacterial properties $^{45}$. NAg was recently incorporated into dental resins ${ }^{51}$. Their small particle size and large surface area could enable them to release more $\mathrm{Ag}$ ions at a low filler level, thereby reducing $\mathrm{Ag}$ particle concentration necessary for efficacy ${ }^{47}$. Ag salt when mixed with primer or adhesive. The $\mathrm{Ag}$ ions in the resin agglomerated to form nanoparticles that became part of the resin ${ }^{52}$.

The results of the present study demonstrated a significant increase in shear bond strength of Nano-Bond adhesive containing nanoparticles of silver (NAg) with concentration $0.05 \%$ than NanoBond adhesive system without additives. This may be contributed to NAg-containing bonding agent was antibacterial activity not only on its surface, but also away from its surface. This indicates that NAg-containing resin has a long-distance killing capability, likely due to the release of $\mathrm{Ag}$ ions ${ }^{53}$. When NAg are dispersed in bonding agent at low concentrations, thermal and mechanical properties, as well as biostability and antibacterial ability, are improved ${ }^{54}$, which reduce or eliminate the interfacial stress concentration within composite/ adhesive bonding resin complex ${ }^{55}$.

Improvement of strength with addition of nanoparticles of silver (NAg) may have been due to inherent characteristics of the NAg particles. NAg possesses strong ionic interatomic bonding, giving rise to its desirable material characteristics that is shear strength. 


\section{CONCLUSION}

On the basis of this study, we can conclude that:

The adhesive shear strengths are high for metal bracket bonded by Nano-Bond adhesive system containing nanoparticles of silver (NAg) with concentration $0.05 \%$ than ceramic bracket.

Further studies are needed to investigate its effect on other mechanical and physical properties with different concentrations.

\section{REFFERENCE}

1- Kocadereli I, Canay S, Akca K. Tensile bond strength of ceramic orthodontic brackets bonded to porcelain surfaces. Am J Orthod Dentofacial Orthop 2001;119:617-20.

2- Theodorakopoulou L, Sadowsky P, Jacobson A, Lacefield W. Evaluation of the bonding characteristics of 2 ceramic brackets: an in vivo study. Am J Orthod Dentofacial Orthop 2004;125:329-36.

3- Fernandez L, Canut J. In vitro comparison of the retention capacity of new aesthetic brackets. Eur J Orthod 1999;21:71-7.

4- Olsen M, Bishara S, Boyer D, Jakobsen J. Effect of varying etching times on the bond strength of ceramic brackets. Am J Orthod Dentofacial Orthop 1996;109:403-9.

5- Bishara S, Olsen M, Von Wald L. Evaluation of debonding characteristics of a new collapsible ceramic bracket. Am J Orthod Dentofacial Orthop 1997;112:552-9.

6- Bishara S, Fonseca J, Fehr D, Boyer D. Debonding forces applied to ceramic brackets simulating clinical conditions. Angle Orthod 1994;64:277-82.

7- O Brien K, Read M, Sandison R, Roberts C: A visible light activated direct bonding material: an in vivo comparative study. Am J Orthod Dentofacial Orthop.1989; 95:348-51.

8- Stanford S, Wozniak W, Fan P: The need for standardization of test protocols. Semin Orthod 1997; 3:206-09.

9- Fox N, Cabe J, Buckley J: A critique of bond strength testing in orthodontics. Br J Orthod 1994; 21:33-43.

10- Millett D, Cabe J: Orthodontic bonding with glass ionomer cement- a review. Eur J Orthod 1996; 18:385-99.

11- Gaffey P, Major P, Glover K, Grace M, Koehler J: Shear/ peel bond strength of repositioned ceramic brackets. Angle Orthod 1995; 65:351-7.
12- Littlewood S, Redhead A: Use of jigs to standardize orthodontic bond strength. J Dent 1998; 26:539-45.

13- Buonocore M: A simple method of increasing the adhesion of acrylic filling materials to enamel surface. J Dent Res $1955 ; 34: 49-53$

14- Craig G: (2002) Restorative dental material $11^{\text {th }}$ edition. Mosby, Year Book Inc. St. Louis. USA. Chap.9: 231-57.

15- Jokstad A, Bayne S, Blunck U, Tyas M, Wilson N: Quality of dental restorations. FDI Commission Projects 2-95. Interl Dent J 2001; 51:117-58.

16- Sakaguchi R: Review of the current status and challenges for dental posterior restorative composites: clinical, chemistry, and physical behavior considerations. J Dent Mater 2005; 21:3-6.

17- Gogos C, Stavrianos C, Kolokouris I, Papadoyannis I, Economides N: Shear bond strength of AH-26 root canal sealer to dentin using three dentin bomding agents. J Dent 2003; 31:321-26.

18- Ikemura K, Tay F, Endo T, Pashley D: A review of chemical-approach and ultramorphological studies on the development of fluoride-releasing dental adhesives comprising new pre-reacted glass ionomer (PRG) fillers. J Dent Mater 2008; 27:315-29.

19- Park J, Ye Q, Topp E, Misra A, Kieweg S, Spencer P: Water sorption and dynamic mechanical properties of dentin adhesives with a urethane-based multifunctional methacrylate monomer. J Dent Mater 2009; 25:1569-75.

20- Garcia-Godoy F, Kramer N, Feilzer A, Frankenberger R: Long-term degradation of enamel and dentin bonds: 6-year results in vitro vs. in vivo. J Dent Mater 2010; 26:1113-18.

21- Shinohara M, De Goes M, Schneider L, Ferracane J, Pereira P, Hipolito V, et al: Fluoride-containing adhesive: durability on dentin bonding. J Dent Mater 2009; 25:1383-91

22- Swift E: Critical appraisal. Options for dentin/enamel bonding: part IV. J Esth and Rest Dent 2010; 22:270-75.

23- Imazato S, Kinomoto Y, Tarumi H, Ebisu S, Tay F: Antibacterial activity and bonding characteristics of an adhesive resin containing antibacterial monomer MDPB. J Dent Mater 2003; 19:313-19.

24- Imazato S, Tay F, Kaneshiro A, Takahashi Y, Ebisu S: An in vivo evaluation of bonding ability of comprehensive antibacterial adhesive system incorporating MDPB. J Dent Mater 2007; 23:170-6. 
25- Wegdan: Effect of cutting bur on the bond strength of a self-etching and one bottle nanofilled adhesives to enamel and dentin. Egy Dent J 2005;51:1171-79

26- Antonucci J, Zeiger D, Tang K, Lin-Gibson S, Fowler B, Lin N: Synthesis and characterization of dimethacrylates containing quaternary ammonium functionalities for dental applications. J Dent Mater 2012; 28:219-28.

27- Cheng L, Weir M, Xu H, Antonucci J, Kraigsley A, Lin $\mathrm{N}$, et al: Antibacterial amorphous calcium phosphate nanocomposite with quaternary ammonium salt and silver nanoparticles. J Dent Mater 2012; 28:561-72.

28- Cheng L, Weir M, Zhang K, Xu S, Chen Q, Zhou X, et al. : Antibacterial nanocomposite with calcium phosphate and quaternary ammonium. J Dent Res 2012; 91:460-66.

29- Cheng Y, Zeiger D, Howarter J, Zhang X, Lin N, Antonucci J, et al: In situ formation of silver nanoparticles in photocrosslinking polymers. J Bio Mater Res 2011; 97:124-31.

30- Alani A and Toh C: Detection of microleakage around dental restorations. J Oper Dent 1997; 22:173-5.

31- Causton B: Improved bonding of composite restoration to dentin. A study in vitro of the use of a commercial halogenated phosphate ester. J Oper Dent 1984; 156: 93-98.

32- Yoshiharu I, Suzuki S and Shungi F: Enamel wear of modified porcelain. J. Am Dent Asso 2000; 13:315-23.

33- American Dental Association Council on Scientific affairs (2002): American National Slandered $\backslash$ American Dental Association (ANSI\ADA) No.27: Dentistry-polymerbased filling restoration and lating material. P263-267.

34- International Organization for Standardization (ISO) (2001) mechanical specification 11405; Dental materials, testing of adhesion to tooth structure.

35- Jemt T, Karlsson S, Hedegard B: Mandibular movement in young adults recorded by internally placed light-emitting diode. J Prosthet Dent 1979; 42:669-73.

36- Drummond J, Novickas D, Lenke J: Physiological aging of an all-ceramic restorative material. J Dent Mat 1991; 25: $133-38$.

37- Correr Sobrinho L, Cattell MJ, Glover RH, Knowles $\mathrm{J}$ : Investigation of the dry and wet fatigue properties of three all-ceramic crown systems. Int J Prosthodont 1998; 11:255-62.
38- Attia A, Kern M: Influence of cyclic loading and luting agents on the fracture load of two all-ceramic crown systems. J Prosthet Dent. 2004; 92:551-6.

39- Att W, Kurun S, Gerds T, Strub JR. Fracture resistance of single-tooth implant-supported all-ceramic restorations: an in vitro study. J Prosth Dent. 2006; 95:111-6.

40- Labella R, Lambrechts P, Meerbeek B, Vanherle G: Polymerization shrinkage and elasticity of flowable composites and filled adhesives. J Dent Mat 1999; 15:128-37.

-14 -Katona T, Long R: Effect of loading mode on bond strength of orthodontic brackets bonded with 2 systems. Am J Ortho Dent Orthop. 2006; 129:60-4.

42- Özcan M, Vallittu P, Peltomäki T, Huysmans M, Kalk W: Bonding polycarbonate brackets to ceramic: effects of substrate treatment on bond strength. Am J Orthod Dent Orthop. 2004; 126:220-7.

43- Hossam Z, Ola I, Inas E, Mohamed A, Ali I: Bond strength and morphological interface of self-etching adhesives to demineralized and remineralized enamel. J Dent Scie 2013; 8, 287-295.

44- Rihito K, Tohru H, Kazutaka K: Bonding and debonding characteristics of orthodontic brackets to human enamel using modified 4-META/MMA-TBB resin. J orthodont wave 2007 ; 66:129-138.

45- Meiers J, Kazemi R, Donadio M: The influence of fiber reinforcement of composites on shear bond strength to enamel. J Prosth Dent 2003; 89:388-93.

46- Cheng Y, Zeiger D, Howarter J, Zhang X, Lin N, Antonucci $\mathrm{J}$, et al: In situ formation of silver nanoparticles in photo crosslinking polymers. J Bio Mater Res 2011; 97:124-31.

47- Gale M, Darvell B: Thermal cycling procedures for laboratory testing of dental restorations. J Dentofac 1999; 27:89-99.

48- Oilo G: Bond strength testing- what does it mean? Int Dent J 1993; 17:492-98.

49- Sudsangiam S, Van Noort R: Do dentin bond strength test serve a useful purpose. J Adh Dent 1999; 1:57-67.

50- Kemp- Scholte C, Davidson C: Marginal sealing of curing contraction gaps in class $\mathrm{V}$ composite resin restorations. J Dent Res 1988, 67: 841-45.

51- Morones J, Elechiguerra J, Camacho A, Holt K, Kouri $\mathrm{J}$, Ramirez $\mathrm{J}$, et al: The bactericidal effect of silver nanoparticles. Nanotechnology 2005; 16:2346-53. 
52- Fan C, Chu L, Rawls H, Norling B, Cardenas H, Whang $\mathrm{K}$ : Development of an antimicrobial resin- a pilot study. J Dent Mater 2011; 27:322-28.

53- Cheng Y,Zeiger D, Howarter J, Zhang X, Lin N, Antonucci $\mathrm{J}$, et al: In situ formation of silver nanoparticles in photo cross linking polymers. J Bio Mat Res 2011; 97:124-31.
54- Cheng L, Zhang K, Melo M, Weir M, Zhou X, Xu H: Antibiofilm dentin primer with quaternary ammonium and silver nanoparticles. J Dent Res 2012; 91:598-04.

55- Chou C, Hsu S, Chang H, Tseng S, Lin H: Enhanced thermal and mechanical properties and biostability of polyurethane containing silver nanoparticles. Polym Degrad Stab. 2006; 91:1017-24. 